\title{
PRÁTICA EXPLORATÓRIA, ESPAÇOS FORMATIVOS E A EDUCAÇÃO CRÍTICA DE PROFESSORES DE INGLÊS: O OLHAR HÍBRIDO DE UMA PROFESSORA FORMADORA
}

\author{
Isabel Cristina Rangel Moraes BEZERRA - UERJ ${ }^{8}$
}

RESUMO: Neste artigo discuto o processo de formação inicial de licenciandos de língua inglesa em uma universidade pública partindo de minha prática de professora formadora. Problematizo especialmente a relação que alguns espaços formativos têm naquele processo, a necessidade de adoção e implementação de uma educação linguística crítica e reflexiva para licenciandos de língua inglesa. Finalmente, proponho a Prática Exploratória como uma proposta ética e reflexiva de conduzir a formação docente inicial.

PALAVRAS-CHAVE: Prática Exploratória; formação inicial de professores; ensino de inglês.

ABSTRACT: In this paper I discuss the pre-service education process of English teachers in a public university, having my own practice as teacher educator as the starting point. I problematize in particular the relation that some formative contexts can have in the process, the need to adopt and to implement a model of critical linguistic education to future English teachers. Finally, I propose Exploratory Practice as a possible ethical and reflective framework upon which the process of teacher initial education can be developed.

KEY WORDS: Exploratory Practice; pre-service education; English teaching.

\section{CONSIDERAÇÕES INICIAIS}

A construção do saber do professor pré-serviço deve apontar para uma formação crítica e teoricamente informada (MOITA LOPES, 2000 e 2003), envolvendo questões enfrentadas pelos professores regentes em seu cotidiano (MILLER, 2010). Neste artigo, proponho-me a fazer uma breve reflexão sobre a articulação teoria - planejamento prática docente, apresentando uma possibilidade para a condução da formação docente. A partir de minha experiência enquanto professora formadora e professora de ensino médio, discuto como a Prática Exploratória (ALLWRIGHT, 2006, 2005; ALLWRIGHT e HANKS, 2009; GIEVE e MILLER, 2006) pode ser um encaminhamento dado a este processo especialmente devido aos princípios que orientam esta forma de ensinar, aprender e refletir sobre a prática docente.

\footnotetext{
${ }^{8}$ Doutora em Letras pela Pontifícia Universidade Católica do Rio de Janeiro; docente da Universidade do Estado do Rio de Janeiro.
} 


\section{A INTERLOCUÇÃO ENTRE ESPAÇOS FORMATIVOS}

Em consonância com as novas orientações para a oferta de cursos de graduação para a formação de professores da educação básica (CNE/CP 1/2002, CNE/CP 2/2002) propostas pelo MEC, o curso de Letras da instituição onde trabalho foi reformulado. Por isso, licenciandos passaram a ter contato com questões teóricas para o ensino/aprendizagem de língua estrangeira (LE) desde o terceiro período da graduação na disciplina de Metodologia do ensino de inglês e, nos períodos seguintes, em Fundamentos e prática de ensino de língua inglesa I, II e III. Tais disciplinas propiciaram um caminhar mais ostensivo em direção à articulação teoria-prática que antes só acontecia nos dois últimos períodos da graduação. Finalmente, os licenciandos iniciam sua ação docente em salas de aula em Estágio Supervisionado de Língua Inglesa I (em escolas de ensino fundamental), II (em escolas de ensino médio) $e$ III (em cursos de idiomas, ONGs, empresas, entre outros contextos). Seguindo a orientação das ementas, os licenciandos têm a oportunidade de produzir material, propor oficinas, ministrar aulas e o que mais for possível dentro da proposta pedagógica das escolas/ dos cursos de idiomas em que se inserirem, estando sob a orientação do professor formador em colaboração com o professor regente.

Tal percurso de formação parece refletir uma questão apontada por Tardif (2002, p.17), quanto à construção de saberes docentes, quando este autor afirma que "as relações dos professores com os saberes nunca são estritamente cognitivas: são relações mediadas pelo trabalho que lhes fornece princípios para enfrentar e solucionar situações cotidianas". Embora Tardif refira-se ao professor em serviço, acredito que esta relação possa ser estendida ao licenciando que, mesmo não tendo ainda com a prática docente um vínculo de trabalho no sentido estrito, começa a se construir profissionalmente durante o estágio ou em experiências de várias ordens propiciadas pelas disciplinas que instigam o pensar e o agir docentes. Tais experiências fazem parte de sua história de vida profissional em construção e começam a ser uma referência para tomadas de decisões e ações. Conforme Prabhu (1997), tais elementos configuram o senso de plausibilidade do professor - o qual é construído ainda no período em que o professor é aluno, antes e durante o curso universitário - envolvendo valores, crenças, as leituras que faz da teorização sobre ensinar e aprender. À medida que o licenciando avança no 
processo de formação profissional, seu senso de plausibilidade vai sendo reformulado ao se envolver em novos eventos de docência. Cabe, ainda, ressaltar que, por estarmos vivenciando o momento do pós método (KUMARAVADIVELU, 1994), o que mais importa é co-construir com o licenciando referenciais teóricos que lhe permitam estabelecer um diálogo constante, crítico e reflexivo com a sua prática, não utilizandoos aleatoriamente; enfim, não fazendo de sua prática uma colcha de retalhos na qual se misturam diversos e, por vezes, conflitantes aportes teóricos.

Paralelamente à formação universitária, o que vejo, na condição de professora formadora, é a entrada de alguns licenciandos de língua inglesa no mercado de trabalho bem cedo, i.e., antes mesmo de cursarem disciplinas voltadas para o ensinoaprendizagem de LE na universidade. Consequentemente, costumam atuar em salas de aulas de cursos de idiomas ou escolas particulares - já com remuneração - por vezes no segundo período do curso universitário, ensinando inglês para crianças, para alunos de níveis iniciais ou para alunos de ensino fundamental e médio.

A vivência profissional iniciante em tais contextos leva-os ao contato com métodos e metodologias que, se não discutidos na universidade, podem passar a representar a única referência concreta para a docência, em um retorno à era 'prémétodo'. Isto não significa que os métodos e as metodologias norteadores das práticas docentes de tais contextos sejam necessariamente equivocados. Todavia é preocupante quando licenciandos os assumem como condutores de seu fazer sem qualquer reflexão. Muitos deles parecem, inclusive, não perceber que são posicionados institucionalmente apenas como implementadores das idéias de proponentes de certos métodos e de autores de livros. É preciso problematizar tal atuação que se torna parte da formação profissional tão logo esses alunos vivenciam o ensinar língua inglesa nestes contextos, ao mesmo tempo em que começam a discutir formas de ensiná-la na universidade.

Há, portanto, no processo de formação docente, a sobreposição de espaços formadores - universidade, escola (experiência pessoal e estágio), escola/curso (trabalho). Consequentemente, o licenciando pode buscar o aprendizado de técnicas de ensino e não a construção de saberes informados, considerando a sócio-história na qual estão imersos e agindo discursivamente.

FAZENDO UMA LEITURA DO PROFESSOR COMO INTELECTUAL NA FORMAÇÃO E NA PRÁTICA DO PROFESSOR DE INGLÊS 
Nesta seção, busco inspiração na reflexão de Giroux (1997) voltada para a formação dos professores como intelectuais a fim de pensar especificamente no professor de inglês. Inicialmente, conforme o autor (ibid.) discute, existe a necessidade de se questionar a formação docente que se configura com ênfase apenas em seu viés técnico, uma vez que, mesmo quando vistos como técnicos de alto nível em certos contextos profissionais, os professores não passam de cumpridores de metas propostas por especialistas, cabendo-lhes a ação e não o pensar sobre o trabalho. Partindo desta premissa, cabe à universidade e, mais especificamente, aos professores formadores, repensar "a natureza e a finalidade da preparação dos professores, dos programas de treinamento no trabalho e das formas dominantes da escolarização" (GIROUX, 1997, p.157-158).

Essa visão evidencia um olhar à universidade e à escola como espaços de legitimação. Seria necessário que professores formadores, professores regentes e professores em formação identificassem quais seriam as ideologias, as visões de mundo, as formas de escolarização legitimadas, as metodologias privilegiadas, para, em seguida, refletirem coletivamente sobre questões como aquelas elencadas abaixo. Tomando por referência a proposta de Giroux (1997), as questões que se seguem podem contribuir para tornar o pedagógico mais político e o político mais pedagógico se aqueles três atores sociais refletirem sobre:

[a] Como acontece a inserção do profissional de línguas nos contextos educacionais: como intelectual transformador ou como implementador de instruções e currículos?

[b] Como esse profissional vê e estabelece a sua relação com seus alunos? Que papel o afeto parece ter (ou não) nesta relação?

[c] Que foco é dado à língua inglesa ensinada aos licenciandos na universidade?

[d] Por que e para quê os alunos aprendem língua inglesa na educação básica e em cursos de idiomas?

[e] Como acontece a inserção da língua inglesa na sua sala de aula de ensino fundamental e médio? A quem serve? Que discursos e práticas sociais ela colabora para legitimar ou desconstruir?

[f] De que maneira a formação do professor formador, bem como os aportes teóricos que configuram os seus entendimentos sobre língua e sobre ensinar/aprender, influenciam o processo de formação de novos professores?

Articuladas a este processo reflexivo, ações poderiam ser desenvolvidas por professores formadores, professores regentes - igualmente entendidos como formadores 
de novos professores - licenciandos e, da mesma forma, os alunos de ensino fundamental e médio. Tais ações configurariam uma prática docente e uma prática discente voltadas para o mapeamento de práticas e discursos naturalizados que se mantêm legitimando saberes, reforçando instâncias locais de poder, oprimindo, produzindo preconceitos e atitudes de intolerância com a diferença. Ao longo do tempo, aquelas práticas e discursos poderiam ser reconstruídos em outras bases através do próprio discurso, entendido enquanto instância de ação social (FAIRCLOUGH, 1996; MOITA LOPES, 2003). Abaixo são elencadas algumas ações possíveis:

[a] construção de espaços discursivos em que aqueles professores formadores, licenciandos, professores regentes e alunos pudessem ouvir uns aos outros e apresentar suas questões. Isto poderia ser desenvolvido de várias formas, mas opto por apontar a Prática Exploratória - PE de agora em diante - (MILLER et. al., 2008) como um caminho possível como será explicitado adiante;

[b] condução do trabalho pedagógico tomando por foco os gêneros discursivos, as práticas sócio-discursivas que lhes dão origem e os diversos textos que circulam na sociedade (PCN-LE, 1998). Não se trata de uma proposta de 'ensino para a comunicação' como se houvesse a possibilidade de interação discursiva sem negociação, conflito, luta pelo poder ou debate (PCN-LE, 1998), apenas usando-se o conhecimento da língua e dos gêneros para se fazer entender. Trata-se de construir entendimentos sobre a gênese dos gêneros, o processo de circulação dos textos, i.e., entender que a circulação de textos na sociedade está diretamente relacionada a questões de luta e de poder, de naturalização de discursos (FAIRCLOUGH, 1996) e, consequentemente, sobre quem tem/pode ter acesso aos mesmos na sociedade;

[c] questionamento das práticas docentes em vigor - i.e., a serviço de quem está a prática desenvolvida nas escolas (e em cursos de idiomas) bem como os recortes de conteúdos feitos - seja por especialistas/técnicos da área de educação dos órgãos oficiais, por coordenadores ou alguma equipe específica da escola/ do curso, pelo próprio professor. Neste sentido, caberia questionar, por exemplo, o que significa ensinar os alunos a conjugar o verbo to be ou a memorizar listas de palavras em um contexto sócio-histórico em que é preciso conhecer gêneros discursivos diversos para compreendê-los e/ou produzi-los. O primeiro recorte de conteúdos mantém uma idéia fragmentária do idioma a ser ensinado; ao passo que o segundo pode contribuir para o engajamento do usuário-aprendiz daquela LE em práticas discursivas e sociais; 
[d] questionamento sobre a forma como o trabalho do professor se desenvolve em instituições de ensino e dos papéis que ele precisa desenvolver - i.e., em que medida o trabalho do professor de inglês está sujeito a uma lógica de mercado quando, em cursos de idiomas, por exemplo, ele tiver que assumir tarefas que não têm um caráter pedagógico/acadêmico, mas que lhes são impostas tais como a venda de produtos aos alunos: certificações, viagens, etc.;

[e] questionamento sobre o valor agregado à língua inglesa no currículo da educação básica, considerando-se a carga horária alocada para a mesma na grade curricular, a formação exigida ao docente para que possa ministrá-la. Por outro lado, seria questionado o tratamento local dado pelos próprios professores, coordenação e direção à LE nas práticas pedagógicas de uma dada escola, valorizando ou não aquele idioma;

[f] questionamento sobre a inserção de tecnologias da informação e da comunicação nas escolas e cursos - i.e., em que medida elas são introduzidas para substituir as lousas originais e manter o professor no papel de implementador ou, diferentemente, para serem utilizadas como ferramentas para a construção de conhecimento, sendo o professor o intelectual transformador que entende o porquê desta inserção e define para quê/como vai inserir o aparato tecnológico em sua prática.

Considerando os itens acima, um pequeno recorte diante das inúmeras ações possíveis, justifica-se a necessidade de articulação daquelas questões aos processos de formação docente inicial e continuada. Seria uma forma de envolver todos aqueles participantes já mencionados no sentido de mapear como se instauram práticas docentes no aqui e agora da pós-modernidade, bem como a que lugares sociais e discursivos tais práticas podem conduzi-los.

\section{O PLANEJAMENTO E A VIVÊNCIA DA PRÁTICA: REFLEXÃO E 'OPORTUNIDADES DE APRENDIZAGEM'}

Espera-se do professor de inglês - e do licenciando - que planeje a sequência didática a ser implementada e que esta contribua para a construção de conhecimentos antes de efetivamente interagir com os alunos em sala de aula. Ulichny (1996) afirma que uma abordagem para compreensão da metodologia utilizada pelo professor deve passar pela prática da sala de aula ou evento de ensino. Isto seria necessário uma vez que nesse evento haveria, por parte do professor regente - e também do professor em 
formação - a tentativa de dar conta e agir segundo os entendimentos que os alunos parecem estar construindo através de suas ações discursivas. Tal monitoramento teria por foco o engajamento discursivo que acontece ou não durante a implementação das atividades de ensino. Da mesma forma, seriam consideradas as habilidades e motivações ou ainda a falta de interesse que os alunos parecem apresentar. Assim, a asserção de Ulichny (1996) é relevante, pois aponta para além da questão puramente técnica da ação profissional já estabelecida ou em formação.

Esta percepção local pode fazer com que o professor mude sua agenda, a dinâmica da aula e, até mesmo, os objetivos que deveriam ser alcançados no caso de o professor perceber que os alunos estivessem aquém/ além do que havia sido planejado ou que o engajamento discursivo às práticas de sala de aula não estivesse sendo co-construído como será ilustrado mais adiante. Embora o licenciando possa apresentar uma flexibilidade menor nesse sentido, dado o seu momento de formação, tais modificações poderiam acontecer em micro aulas e em aulas práticas que deve ministrar durante o estágio. A análise conjunta de tais tomadas de decisões por parte do professor formador, do licenciando e do professor regente sobre o que acontece no momento de efetivação da aula no estágio pode ajudar o licenciando a perceber como consegue lidar com as diferentes situações. Da mesma forma, tal análise pode ajudá-lo a compreender como tais decisões se coadunam com as crenças, teorias e intuições que traz, sendo, por vezes, colocadas em xeque.

Assim, no processo de formação, é preciso haver espaço não apenas para a formação do professor-reflexivo, mas também para a construção com o licenciando do seguinte entendimento: o esforço pedagógico precisa contribuir para que o aluno da escola básica aproprie-se do espaço discursivo em sala de aula, utilizando a LE que aprende para agir no mundo social e não mais para estocá-la em algum ponto de sua memória ou mesmo esquecê-la por não conseguir articular o que aprendeu às possibilidades de uso da mesma. Para o professor de inglês em formação significa entender que

aprender uma língua significa aprender a se envolver nos embates discursivos que os discursos a que somos expostos em tal língua possibilitam, o que é igual a saber que estamos discursivamente posicionados de certos modos e que podemos alterar esses modos, para construir outros mundos sociais melhores ou outros significados sobre quem somos na vida social, de maneira a alterar os significados que nos excluem como também aqueles que excluem os outros. (MOITA LOPES, 2003, p. 45-46) 
Para o licenciando, portanto, talvez tais questões fiquem mais patentes quando vivenciar, durante as aulas na universidade, o enfoque da língua como ferramenta de ação social (PCN-LE, 1998). Neste viés, não apenas as disciplinas que abordam as questões metodológicas têm uma contribuição a dar, mas também a forma como a língua inglesa é tratada nas aulas de língua, enquanto objeto de estudo e ensino do professor em formação. Trata-se de entender o discurso enquanto construtor de identidades e do mundo social, bem como de planejar e implementar uma aula ou qualquer atividade.

Para que uma formação docente de tal ordem passe a ser construída, torna-se indispensável ao licenciando analisar a sua prática iniciante de forma a configurar uma visão mais acurada sobre como o processo de construção conjunta do conhecimento vaise fazendo. Estaria este de acordo com os recortes teóricos que ele assume para seu fazer? Ele percebe que o conteúdo selecionado sofre a pressão da luta por voz no processo de construção de conhecimentos durante as interações em sala de aula? Ele considera as vozes e os conhecimentos trazidos pelos aprendizes? Caberia, então, ao professor formador propiciar espaços para a discussão dessas questões a fim de que a formação não se configure um pacote fechado, contendo instruções e atividades, as quais devem ser aplicadas aos alunos no cotidiano de ensino de LE através de receitas metodológicas.

Em decorrência desta afirmação, é preciso que o professor-formador enfatize a figura do professor reflexivo, ensejando a construção paulatina de uma prática pedagógica em LE mais adequada, rompendo os entendimentos tradicionais e dogmáticos da prática do professor de LE (MOITA LOPES, 1996). Como assinala Moita Lopes (2000, p.45), seria um percurso

bem diferente da maneira tradicional tecnicista de se formar
professores de línguas, que os coloca em uma constante procura pelas
chamadas novidades sem que, em sua formação, entendam como essas
chamadas novidades são elaboradas. A ausência desta reflexão de
natureza epistemológica impossibilita que os professores venham
assumir a responsabilidade direta por suas práticas em sala de aula.
Esta concepção da formação do professor, assim, não inclui a
possibilidade de emancipação de um profissional que se quer um
intelectual público.

A citação acima sinaliza como a ação do professor no contexto social avança da esfera pedagógica para a esfera política com as decorrentes implicações de responsabilidade e engajamento. A sala de aula, portanto, é espaço discursivo para 
reescrituras de visões e entendimentos sobre a vida social, sobre o outro, bem como sobre metodologias para o ensino de LE, sobre o que significa ensinar-aprender inglês no contexto brasileiro. Colaborando para este caminhar, aponto a Prática Exploratória [PE] (ALLWRIGHT 2006, 2002) como uma possibilidade de aliar a prática docente ao viés reflexivo em sala de aula. Seus princípios, conforme Miller et al. (2008), norteiam as ações dos praticantes que buscam entendimentos para suas questões (ou puzzles) que se tornam parte do conteúdo e são articuladas ao planejamento. Busca-se planejar para entender, em ações balizadas pelos seguintes princípios:

Priorizar a qualidade de vida.

Trabalhar para entender a vida em sala de aula ou em outros contextos profissionais.

Envolver todos neste trabalho.

Trabalhar para a união de todos.

Trabalhar para o desenvolvimento mútuo.

Integrar este trabalho com as práticas de sala de aula ou com outras práticas profissionais.

Fazer com que o trabalho para o entendimento e a integração sejam contínuos.

(MILLER et al. (2008,p.147- grifos no original)

Segundo a proposta teórico-metodológica e ético-filosófica que constitui o cerne desta forma de ensinar-aprender/refletir-pesquisar envolvendo todos os praticantes, o foco recai sobre a qualidade de vida da sala de aula, sem, contudo, entendê-la como algo à parte do que se vive e age fora de suas paredes (GIEVE e MILLER, 2006; MORAES BEZERRA, 2007, 2010). Como asseveram Miller et al. (2008, p.155), ao comentar questões de professores e alunos, "é dentro deste contexto, destas tristes realidades, [...] que muitas vezes enfrentamos o desafio de trabalhar com a Prática Exploratória na escola”. Certamente há espaço para questões que os levem a se engajarem em reflexões acerca de vivências positivas. Porém, neste cenário de incertezas no qual se inscrevem as vivências do homem pós moderno, nem a escola nem a universidade estão em situação de exceção e, por isso mesmo, muitos puzzles costumam abordar porquês envolvendo a dificuldade da relação professor-aluno, as dificuldades em trabalhar em determinados espaços educacionais, a falta de voz dos alunos, a falta de valorização do docente, o sofrimento humano.

Desta forma, a proposta da PE pode colaborar no processo de formação docente exatamente por que não enfatiza o viés técnico, mas o ético-reflexivo. Nas aulas da universidade em que se discuta o planejamento, a PE pode colaborar para a ressignificação das micro-aulas e das aulas práticas nas escolas. Segundo Miller et al 
(2008, p.150), tais aulas devem ser vistas “como 'trabalho para entender' e não como 'oportunidades para demonstrar que dominamos micro-habilidades ou técnicas"”. Por conseguinte, o licenciando buscará refletir sobre o que ele conseguiu entender e construir em termos de saberes profissionais a partir daquela oportunidade. Ele pode e deve envolver os colegas da universidade, o professor regente e os alunos em sua sala de aula de estágio. Conforme Allwright (2005), muda-se de perspectiva, pois ao invés de 'pontos a serem ensinados', volta-se para 'questões a serem entendidas', propiciando assim a emergência de oportunidades de aprendizagem (learning opportunities) (ibid.). Ademais, ao invés de refletirem e pesquisarem para 'resolver problemas', os praticantes voltam-se para a "tentativa de compreender os fatores que afetam a qualidade de vida na sala de aula de língua, ao invés de focar diretamente na tentativa de se alcançar uma alta qualidade de trabalho" (ALLWRIGHT, 2006, p.16).

Allwright e Hanks (2009) lembram que o planejamento, embora importante, não é garantia de que o aluno aprenderá. Ele é uma possibilidade que se concretizará na aula a partir das ações discursivas dos participantes. Esta asserção reforça a necessidade de se 'planejar para buscar entendimentos' e não para controlar o que pode acontecer já que muitos professores e licenciandos que já tiveram a experiência de implementar o mesmo planejamento em turmas diferentes sempre saem de cada um destes eventos com a percepção de que aulas diferentes se configuraram já que cada turma é constituída por alunos diferentes, com expectativas, histórias de vida e visões de mundo diferentes.

O planejamento de aulas, na perspectiva da PE, assume uma característica integrativa, uma vez que, mantendo o seu viés pedagógico, i.e., o ensino da língua estrangeira, também contempla a ação pela busca de entendimento dos praticantes envolvidos. Assim, professores e alunos de qualquer nível de ensino têm seu agir ressignificado. Todos são intelectuais reflexivos.

\section{O DITO E O FEITO: VIVENCIANDO A PE NA ESCOLA E NA UNIVERSIDADE ${ }^{9}$}

Para tentar ilustrar a proposta que trago, fundamentada pelos princípios da $\mathrm{PE}$, passo a relatar a minha experiência enquanto professora de inglês do curso normal na rede estadual de ensino e professora formadora em uma universidade pública estadual, além de participante do grupo de Prática Exploratória do Rio de Janeiro - provocando

\footnotetext{
${ }^{9}$ Enfatizo que, nesta seção, relato uma experiência profissional cuja vivência inspirou a produção deste artigo. Consequentemente, o estilo de narrativa adotado é intencional.
} 
um estar híbrido nestes contextos. Nesta experiência, envolvi duas turmas: uma do curso normal e outra da universidade. Ao envolver a turma CN1007 do primeiro ano do curso normal, trabalhamos para juntos entender os seguintes puzzles que me intrigavam à época: 'Por que meus alunos conversam tanto? Por que há momentos em que parece que meus alunos não estão se importando com a aula?' Eu desejava, acima de tudo, entender como alunos de um curso de formação de professores para atuação nas primeiras séries do ensino fundamental viam-se neste curso, que valores traziam para o mesmo, que valores haviam construído em relação à escola e à educação.

Para viver esta experiência, desenvolvi uma sequência didática a ser desenvolvida em aulas cujo foco maior recai sobre o ensino de leitura. Tal sequência iniciou-se quando os alunos responderam individualmente e em português ao seguinte questionamento: If I were a teacher today, would I like to have myself as a student? Why? Parti do princípio de que o questionamento em inglês conduziria a três instâncias de ação cognitiva: [a] seria uma possibilidade de os alunos acionarem os conhecimentos que possuíam sobre a língua inglesa para responder aquelas perguntas; $[\mathrm{b}]$ haveria o acionamento de conhecimento de mundo sobre ensino, escola, etc. que seria útil para o texto que seria tratado a seguir; [c] seria o início de um percurso de reflexão que ajudaria a envolver todos na busca de entendimentos.

A próxima etapa aconteceu na aula seguinte quando os alunos tiveram contato com o conjunto de respostas dadas pelos colegas à pergunta que iniciou a sequência didática. Separei-as em três categorias - sim, não, mais ou menos -, conforme apresentado abaixo com excertos de algumas das respostas dos alunos:

Sim...
[1]"porque sou uma menina interessada. Às vezes fico desanimada, mas no fundo eu gosto de
estudar."
[2]"pois sou uma boa aluna, entendo a matéria com facilidade e gosto de estudar. Sei que
gostaria muito de ter uma aluna como eu. Sei que posso acertar ou errar os exercícios ou as
avaliações, mas todos fazem isso. Não é errando que se aprende? Então sou uma boa aluna."
[3]"porque não sou uma pessoa bagunceira e difícil de lidar. Não tiro nota dez, mas também
não tiro nota zero. Não tive até agora muitas dificuldades nas matérias e também nunca fui
de me esforçar muito e o pouco que me esforço é o suficiente para passar de ano e nenhum
professor me odiar e nem me achar péssima aluna."

No excerto 1, a resposta da aluna parece indicar que sua aparente falta de envolvimento na aula não é algo permanente, pois ela se vê como alguém que gosta de estudar e, por conseqüência, alguém que valoriza a escola. Apenas ela não o faz dentro do padrão esperado por mim, sua professora. No excerto 2, a aluna também se 
reconhece como boa aluna que gosta de estudar. Ressalto sua percepção sobre a possibilidade de erros como algo positivo e próprio do processo de aprender, especialmente quando questiona 'não é errando que se aprende?' Suas asserções parecem dimensionar a escola como um lugar de experimentação, em que tanto erros quanto acertos devem ser valorizados na vivência acadêmica de cada aluno. Já no excerto 3, uma aluna afirma, 'Não tiro nota dez, mas também não tiro nota zero.' Dentro dos padrões de expectativa da professora isto não era o suficiente, mas para a aluna bastava. A aluna demonstrou clareza na forma como percebia o seu estar na escola ao afirmar 'também nunca fui de me esforçar muito e o pouco que me esforço é o suficiente para passar de ano'. Tal atitude garantia sua sobrevivência acadêmica uma vez que ela percebia que era o suficiente para, 'nenhum professor me odiar e nem me achar péssima aluna'. Ela agia de forma a não ter atritos com seus professores.

\footnotetext{
Mais ou menos...

[4] "Acho que sim. Sou uma boa aluna, mas no início do ano sempre fico um pouco enrolada com as matérias. Também acabo ficando um pouco dispersa quanto à troca de colégio. Não é fácil chegar em um colégio grande aonde não se conhece ninguém."
}

O excerto 4 é extremamente relevante, pois a aluna revela um dado de sua história pessoal que, se não fosse esta atividade, eu provavelmente não teria acesso. Como esse instituto de educação recebe alunos das escolas municipais e privadas em seu entorno, muitas delas bem pequenas, pode haver alunos que passam por momentos difíceis de adaptação ao novo contexto. Assim, a forma de a aluna estar na escola pode ser lida como falta de atenção e desinteresse, o que na verdade não é.

A etapa seguinte da sequência didática consistiu na reflexão da turma sobre todas as respostas dadas pelos colegas às quais tiveram acesso em folhas que foram oferecidas aos grupos que se formaram. Para conduzir tal reflexão, na mesma folha eles encontravam estas outras perguntas:

\footnotetext{
Vamos pensar juntos?

1- Por que será que houve tantas respostas afirmativas [Sim] e poucas negativas [Não] e "mais ou menos"?

2- Ao ler as respostas afirmativas, o que chamou a atenção do grupo? Por quê?

3- Ao ler as respostas negativas, o que chamou a atenção do grupo? Por quê?

4- Pensando nas respostas dadas por vocês e por seus colegas, como os professores do IECP deveriam ver a turma de vocês? Por quê?

5- Por que será que as respostas mencionam basicamente apenas a boa relação com os professores, sem mencionar uma boa relação com os colegas de turma?

6- Considerando todas as respostas, o que a turma deve estar querendo dizer à professora de inglês em relação à atitude da turma durante as aulas? Por quê?
} 
Após discuti-las e respondê-las, cada grupo, planejou e construiu um pôster usando figuras recortadas, desenhos feitos por eles mesmos e frases de forma a retratar a sua reflexão. Depois houve apresentação de pôsteres em que partilharam suas visões. Conforme já indicado, dedico maior proporção do trabalho pedagógico à compreensão de textos em inglês. No entanto, isso não significa que ignore a compreensão oral nem a compreensão/produção escrita, buscando trazer atividades articuladas à temática da sequência didática de forma que os alunos possam se engajar e desenvolver. Desta forma, pedi aos alunos que as frases construídas por eles para fazerem parte do pôster tivessem ao menos algumas palavras em inglês. Para escrevê-las, eles contaram com a minha ajuda, de outros colegas e do dicionário. Seguem abaixo algumas das suas reflexões através de sentenças que não sofreram qualquer tipo de correção, exatamente para estimulá-los a produzir em um idioma que muitos deles achavam tão difícil e tão distante. Alguns utilizaram mais a língua inglesa enquanto outros, menos. Cabe ressaltar que todos tentaram, dentro de suas possibilidades, usá-la para construir asserções que mostravam seus posicionamentos, visões de mundo e entendimentos.

[Grupo 1] Somos uma turma jovem com dreams e ideais, porém bagunceira mas disposta a to learn e a ensinar.

Education nada mais é que cultura. É a troca de conhecimento entre o student e o teacher baseado na determinação do aluno.

[Grupo 2] Somos uma turma willing to create conditions que vão somar na educação de children. Isto é transformar em um good caráter.

We are interessados no que estamos fazendo e que para isto we need nos esforçar ao máximo para que aconteça a diferença na vida de uma child.

Education is transmit, educate, disciplinar e transform para que uma child ou adulto desenvolva uma healthy mind.

[Grupo 3] We are the ones who come to school to try to have a better future.

We want the teachers to know our good side, because the majority of us are afraid to speak about our dark side.

Education is a way to be ready to face the world, without education we will not be able to have a good future to our life.

Através desta experiência, entendi que meus alunos estavam voltados para as aulas, mas não através de padrões de comportamento e de interação que atendessem às minhas expectativas. Ademais, havia comprometimento com a futura profissão, pois embora por vezes repetissem chavões em suas colocações, observei que articulavam o momento histórico em que viviam às necessidades de formação de cidadãos mais envolvidos com o mundo em transformação. Também foi preciso construir um espaço 
discursivo inclusivo para que eles se sentissem mais à vontade para colocar seus questionamentos, medos, dificuldades e sonhos. Foi preciso fazer o exercício de olhar a sala de aula e as relações pelo olhar de meus alunos. Consegui entender como todas estas questões estavam imbricadas e configuravam a 'qualidade de vida' vivida por nós a qual, a princípio, eu achava que não era positiva, nem conducente à aprendizagem. $\mathrm{Na}$ verdade, toda a ação para entender provocou ressignificações na forma como eu percebia meus alunos, bem como refletiu-se na qualidade das relações interpessoais.

$\mathrm{Na}$ universidade, igualmente, tento encaminhar minhas aulas a partir de uma atitude exploratória ao que acontece conosco e partilho com os licenciandos minhas experiências na escola. Por isso, também eles tornam-se praticantes na medida em que, apoiados em leituras e discussões sobre a PE, bem como sobre minhas experiências de professora exploratória, são levados a olhar reflexivamente para a sala de aula (de estágio, do curso/da escola em que trabalham) de forma a propor seus puzzles e a trabalhar para entendê-los. Na sequência, partilham seus entendimentos com todos da turma através da apresentação de seus pôsteres, quando narrativizam suas experiências.

Nesse contexto, a experiência com a turma CN1007, foi relevante não só para mim e para meus alunos do curso normal. Ela, bem como outras, foi partilhada com meus licenciandos da turma de 2010.1 em Fundamentos e Prática de Ensino da Língua Inglesa II (FPELI-II). Além de narrar minhas experiências e de meus alunos, encorajei os licenciandos a tornarem-se praticantes desta forma de ensinar e de aprender em suas salas de aula (aqueles que já trabalhavam), em estágios, ou mesmo olhando nossa própria sala de aula na universidade. Assim, trouxe os pôsteres da turma CN1007, relatei todo o processo coletivo de 'trabalho para entender'. Eles questionaram sobre detalhes da atividade de leitura que eu havia preparado, ficaram surpresos com as colocações dos alunos, questionaram como esta prática se inserira em minha vida profissional e como a escola onde trabalho se colocava em relação a tudo isso. Em seguida, os licenciandos, em duplas trocaram ideias sobre seus contextos de atuação e pensaram em possíveis puzzles sobre a vida em sala de aula. Tais puzzles deveriam ser trabalhados para que a dupla conseguisse construir alguma ação para entender cujas reflexões seriam partilhadas em uma sessão de pôsteres ao final do semestre letivo. Eles teriam tempo para refinar seu olhar à vida em sala de aula, contariam com minha ajuda, teriam a chance de envolver outros praticantes. Não foi uma tarefa fácil para os licenciandos, especialmente entender o que seria ou elaborar um puzzle, porém eu sabia que isso faria parte da 'ação para entender'. Dentre os puzzles que emergiram do 
processo de reflexão, surgiram: 'Porque os alunos têm medo de se expressar oralmente? Por que o ensino de leitura em língua materna não é feito da mesma forma que aprendemos em inglês? Por que a escola trata os homossexuais com violência? Por que planejar é difícil?'.

Eveline e Fenando, que já atuavam como professores de um curso de idiomas, decidiram questionar: 'Are my students really learning?'. Segundo Eveline:

[...] fomos desafiados a construir um pôster que mostrasse um questionamento sobre a sala de aula. Desafio, talvez seja essa palavra que melhor defina os embates iniciais para a construção de nosso primeiro pôster. Pensar em um puzzle que envolvesse o que mais nos intrigava ao olhar a sala de aula não foi tarefa fácil! ${ }^{10}$

A tarefa foi desafiadora para ela, talvez por ter que olhar a sala de aula enquanto espaço para estranhar o dado, buscar algo intrigante, que, no caso desses professores em formação, era o fato de seus alunos não se importarem com as atividades propostas. Segundo ela, "a cada nova atividade, na tentativa de avaliar se os alunos estavam ou não aprendendo, ficávamos frustrados com o desinteresse que tomava conta da sala de aula. [...] todas elas tinham um destino certo: a lixeira." Em um primeiro momento de reflexão, segundo Eveline, ela e o colega perceberam que o ato de jogar as atividades fora era, para eles, uma forma de avaliação do trabalho de ambos, gerando o desconforto. Fernando, nascido em uma família de professores, aponta o mesmo em seu relato:

A minha necessidade de seduzir os meus alunos me fazia perder horas preciosas do meu dia [...] e o resultado do meu trabalho era... o lixo. [...] A priori, eu achava que aquilo me incomodava porque os alunos estavam jogando fora uma ferramenta de avaliação indireta, mas as minhas reflexões me fizeram perceber que o que realmente estava em jogo não era a avaliação do desempenho dos alunos, mas a avaliação deles do meu desempenho. [...] isso me frustrava bastante pois se eu não os seduzia, eu não era um bom professor. Como aluno da faculdade, eu tinha consciência de que toda essa frustração era descabida. Mas como professor não.

O fragmento acima mostra um forte componente afetivo que emergiu através da reflexão. Mostra também como o olhar à frustração sentida por Fernando modificava-se dependendo da faceta identitária que fosse acionada: enquanto licenciando, ele sabia que a atitude dos alunos não significava que fosse mau professor; contudo, enquanto professor não podia evitar ter essa percepção de seu trabalho. O incômodo de ambos

\footnotetext{
${ }^{10}$ Todos os fragmentos foram retirados dos relatos escritos produzidos pelos licenciandos depois da apresentação do pôster e a sua inserção neste artigo foi autorizada pelos mesmos.
} 
provocou um desdobramento do puzzle inicial. Trabalhando para entender junto com os alunos, desenvolveram perguntas a serem feitas durante as aulas: "Por que você estuda inglês? Você gostaria de dar aula para a sua turma? Se você fosse professor, gostaria de ter um aluno como você?" Ressalto como a última pergunta, em especial, remete ao meu próprio puzzle na turma do curso normal.

Eveline revelou como receberam as respostas dos alunos: “[tivemos] como respostas o que nós não esperávamos e, então, chegamos a mais um entendimento: nossos alunos são pessoas! [...] Por não seguir a nossa regra, tudo aquilo nos causou surpresa, e os alunos que antes eram vistos como anjinhos e diabinhos, agora são apenas alunos". Embora pareça óbvia, a constatação da licencianda aponta para uma questão problemática no ambiente escolar, qual seja a prática de se colocar 'rótulos' em alunos, fator que pode provocar a sua exclusão de diversas 'oportunidades de aprendizagem', o não envolvimento em práticas pedagógicas, o sentimento de não pertencimento - o que gera sofrimento. Na sequência, novos puzzles surgiram para ambos, como aponta Eveline:
o que de início foi complicado, a partir de todas as reflexões geradas ao longo da produção do trabalho, novos puzzles surgiram: why my students do not feel interested in extra activities? Why do my students think they don't know English? Is my practice old-fashioned? Why are my students afraid of evaluations of any sort? Are extra activities really that useful?

A quantidade e diversidade de puzzles demonstra um processo reflexivo envolvendo diversos e inter-relacionados aspetos da prática docente em construção. Ressalto, em especial, os puzzles que envolvem as atividades extras. Talvez o primeiro, ao questionar o desinteresse dos alunos em relação a elas, tenha gerado o segundo, que questiona a validade das mesmas. Não seriam as atividades um excesso e, portanto, cansativas, mesmo quando houvessem sido cuidadosamente produzidas e objetivando 'seduzir' os alunos? Outra questão relevante em relação àqueles puzzles diz respeito a questionarem se suas práticas ainda em construção já eram 'old-fashioned'. Essa aparente incoerência, talvez tenha sido provocada pelo fato de aquelas práticas ainda terem como matriz outras, vividas enquanto alunos, e que ainda serviam de base às aulas que ministravam. Seriam tais práticas adequadas ao contexto, aos alunos, ao momento sócio-histórico? Era um momento de revisão crítica do 'senso de plausibilidade' que lhes norteara até então. 
Revendo o percurso, Felipe afirma com relação às reflexões que desenvolveu: "Elas me ajudaram a compreender melhor quem sou, como eu trabalho e como eu penso". Eveline, por outro lado, levou o pôster que reuniu suas reflexões apresentadas na sala de aula de FPELI-II para a sua turma do curso de idiomas. Partilhou suas reflexões, pois acreditou que

\begin{abstract}
seria importante mostrar para os meus alunos a minha reflexão, a forma que eu via a sala de aula e mostrar o resultado da participação deles para o meu entendimento. [...] Ao compartilhar o meu puzzle, comecei a notar que eles também se questionavam e por que não fazer o mesmo trabalho com meus alunos? [...] a partir desse ponto eles começaram a contar o que mais os intrigava ao aprender outra língua e então sugeri a produção do pôster para que neles eles pudessem expressar e também tentar entender o que mais os atingia. [...] e já começaram a montar o pôster com os seguintes puzzles: Why do we study English? Why can we understand but cannot speak English? Why learning English is so difficult?
\end{abstract}

Ainda que se refira a 'meu entendimento' ao apresentar o seu pôster, a atitude de Eveline naquele momento e posteriormente mostra uma instância de busca por ‘desenvolvimento mútuo' e 'envolvimento de todos'. Ela percebeu o potencial pedagógico e exploratório de tal prática. Foi um passo no sentido de encorajar os alunos a trazerem questões do seu interesse e, ao mesmo tempo, aprenderem a língua inglesa como Eveline relatou posteriormente.

\title{
REFLETINDO SOBE A DUPLA EXPERIÊNCIA
}

No primeiro relato, embora o trabalho para entender/ensinar/aprender na primeira situação tenha sido orientado por meus puzzles, isso não significa que apenas minha curiosidade ou necessidade de entender a 'qualidade de vida' constituída por nossas interrelações conduza a minha prática. Meus alunos do curso normal também são agentes neste processo e se engajam em suas buscas pessoais de entendimento e de reflexão via PE. Neste percurso, percebo a construção de uma 'atitude exploratória' no olhar ao mundo social através das questões que costumam abordar.

Na segunda experiência, pude observar em meus alunos da turma de FPELI-II e, especialmente, em Eveline e Fernando, o crescimento e a conscientização profissionais, gerados na prática reflexiva orientada pela PE. Tal atitude exploratória ao contexto e à vida proposta pela PE, se co-construída por professores formadores, licenciandos, professores regentes e alunos, pode vir a abrir o espaço para o encontro das vozes de 
todos os praticantes. Constitui-se um exercício de escuta, de troca, de compreensão. No entanto não se descarta o conflito, bem-vindo à medida em que propicie o cogitar sobre formas diferentes, mas nem por isso excludentes ou piores, de se pensar e estar no mundo social, na vida com outros seres humanos. Para os licenciandos, mais especificamente, é uma oportunidade de, através de suas próprias ações reflexivas, tomarem contato com a complexidade da vida profissional para a qual estão se preparando e de exercerem sua agência (ALLWRIGHT e HANKS, 2009) desde então. Consoante Allwright (2006, p. 14), é um processo de se perceber o ensino e o aprendizado não como trabalho, mas como vida, desde que não se busque 'eficiência de ensino', no sentido tecnicista e reducionista ao qual esta expressão possa remeter.

Das experiências relatadas, percebo a sobreposição dos espaços formativos, ainda que de forma indireta, em relação [a] aos alunos da escola normal, uma vez que busco vivenciar em minha prática um diálogo entre as teorizações que discuto na universidade e minha prática na escola normal; [b] aos licenciados, uma vez que tomam conhecimento com uma professora regente sobre suas práticas desenvolvidas na escola ao mesmo tempo em que ela os envolve em reflexões sobre ensinar LE.

A vivência das experiências de reflexão através da PE pode constituir um momento de construção do senso de plausibilidade (PRABHU, 1997) para os alunos dos dois níveis e também para mim que sou levada constantemente a revisitar minha prática, teorizações e crenças através da PE. Vejo essas oportunidades como uma possibilidade de envolver todos no processo de ensinar-aprender a partir da busca de co-construção de entendimentos, em que agimos enquanto intelectuais críticos.

\section{CONSIDERAÇÕES FINAIS}

Apoiada nos princípios da Prática Exploratória, aponto para uma proposta de mudança de perspectiva sobre a experiência de refletir sobre a sala de aula e as vivências docentes fundamentadas, especialmente, no reconhecimento das potencialidades de todos os participantes, inclusive dos aprendizes da educação básica. Fundamenta-se, além disso, na formação do professor enquanto intelectual, conforme Giroux, e no entendimento não apenas das questões que subjazem as práticas docentes nas escolas e na universidade, mas também no mapeamento dos discursos que permeiam a formação docente, com suas implicações pedagógicas e políticas a partir da 
adoção de uma educação linguística conforme acima discutido. Lembro que Freire (1996, p.30) acentua:

O mundo não é. O mundo está sendo. Como subjetividade curiosa, inteligente, interferidora na objetividade com que dialeticamente me relaciono, meu papel no mundo não é só de quem constata o que ocorre, mas também o de quem intervém como sujeito de ocorrências. Não sou apenas objeto da História, mas seu sujeito igualmente.

Finalmente, o que proponho é o exercício da agência (ALLWRIGHT, 2006, 2005; ALLWRIGHT e HANKS, 2009) por parte de todos envolvidos neste processo de formação docente. Trata-se de uma via de mão dupla para todos os praticantes: todos aprendem. Afinal, embora focando o professor, é possível estender para todos estes praticantes a seguinte asserção de Freire (1996, p.37), uma vez que "não é possível exercer a atividade do magistério como se nada ocorresse conosco". Ainda que imperceptível ou difícil de ser expresso em palavras, a experiência de estar com o outro, ensinando e aprendendo, faz com que muito ocorra com cada um de nós.

\section{REFERÊNCIAS BIBLIOGRÁFICAS}

ALLWRIGHT, D. Six Promising Directions in Applied Linguistics. GIEVE, S.; MILLER, I. K. de. (eds.) Understanding the Language Classroom. Hampshire: Palgrave Macmillan, 2006.

ALLWRIGHT, D. From 'Teaching Points' to 'Learning Opportunities', and Beyond. In: TESOL QUARTERLY, v.39, n.1, 2005.

ALLWRIGHT, D. Putting 'Quality of Life' First: towards a new view of Exploratory Practice. $\quad$ Lancaster: 2002. Disponível em: http:// www.ling.lancs.ac.uk/groups/crile/EPCentre/newsletter2002/html/principles_of_ep. Acesso em maio de 2006.

ALLWRIGHT, D.; HANKS, J. The Developing Language Learner. New York: Palgrave Macmillan, 2009.

FAIRCLOUGH, N. Language and Power. London: Longman, 1996.

FREIRE, P. Pedagogia da Autonomia: saberes necessários à prática educativa. São Paulo: Paz e Terra, 1996.

GIEVE, S.; MILLER, I. K. What do we mean by 'Quality of Classroom Life'? In: GIEVE, S.; MILLER, I. K. (ed.) Understanding the Language Classroom. Hampshire, New York: Palgrave Macmillan, 2006. 
GIROUX, H. A. Os professores como intelectuais: rumo a uma pedagogia crítica da aprendizagem. Porto Alegre: Artes Médicas, 1997.

KUMARAVADIVELU, B. The Post-method Condition: (E)merging Strategies for Second/Foreign Language Teaching. In: TESOL Quarterly, Alexandria, Virginia, v.28, n.1, 1994.

MOITA LOPES, L. P. Oficina de Linguística Aplicada. Campinas: Mercado de Letras, 1996.

MOITA LOPES, L. P. A formação do professor de línguas: discurso, produção de conhecimento e cidadania. In: BOHN, I. Políticas de Ensino de Línguas no Brasil. Florianópolis: Editora da UFSC, 2000.

MOITA LOPES, L. P. A nova ordem mundial, os Parâmetros Curriculares Nacionais e o ensino de inglês no Brasil. In: BÁRBARA, L.; RAMOS, R. de C. G. (orgs.) Reflexões e ações no ensino-aprendizagem de línguas. Campinas: Mercado de Letras, 2003.

MILLER, I. K. Construindo parcerias universidade-escola: caminhos éticos e questões crítico-reflexivas. In: GIMENEZ, T.; MONTEIRO, M.C.G. (orgs.) Formação de Professores de Línguas na América Latina e Transformação Social. Campinas: Pontes Editores, 2010.

MILLER, I. K. et. al. Prática Exploratória: questões e desafios. In: GIL, G.; VIEIRAABRAHÃO, M. H. Educação de Professores de Línguas: os desafios do formador. Campinas: Pontes Editores, 2008.

MORAES BEZERRA, I. C. R. "Com quantos fios se tece uma reflexão?” Narrativas e argumentações no tear da interação. Rio de Janeiro: Departamento de Letras, PUCRio, Tese de Doutorado, 2007.

MORAES BEZERRA, I. C. R. "We could be in touch with real classroom interaction": profissionais em formação em salas de aula de língua inglesa. In: Revista Pesquisas em Discurso Pedagógico, 2010, n.1. Disponível em: http://www.maxwell.lambda.ele.pucrio.br Acesso em setembro de 2010.

PARÂMETROS Curriculares Nacionais: terceiro e quarto ciclos do ensino fundamental: língua estrangeira / Secretaria de Educação Fundamental - Brasília: MEC/SEF, 1998.

PRABHU, N.S. Concept and conduct in Language Pedagogy. In: COOK, G.; SEIDLHOFER, B. (orgs.) Principle and Practice in Applied Linguistics. Oxford: Oxford University Press, 1997.

Resolução CNE/CP 1/2002. Institui Diretrizes Curriculares para a Formação de Professores da Educação Básica em nível superior, curso de licenciatura, de graduação plena. Disponível em http://portal.mec.gov.br/cne/arquivos/pdf/rcp01_02.pdf Acesso em setembro de 2010.

Resolução CNE/CP 2/2002. Institui a duração e a carga horária dos cursos de licenciatura, de graduação plena, de formação de professores da Educação Básica em 
nível superior. Disponível em http://portal.mec.gov.br/cne/arquivos/pdf/CP022002.pdf Acesso em setembro de 2010.

TARDIF, M. Saberes Docentes e Formação Profissional. Petrópolis: Editora Vozes, 2002.

ULICHNY, P. What's in a methodology? In: FREEMAN, D., RICHARDS, J. C. Teacher Learning in Language Teaching. Cambridge: Cambridge University Press, 1996, p. 178-196. 